\title{
Considerations of Unmanned Aircraft Classification for Civil Airworthiness Standards
}

\author{
Jeffrey M. Maddalon ${ }^{*}$, Kelly J. Hayhurst ${ }^{\dagger}$, A. Terry Morris ${ }^{\ddagger}$ \\ NASA Langley Research Center, Hampton, VA, 23681 \\ and \\ Harry A. Verstynen ${ }^{\S}$ \\ Whirlwind Engineering, Poquoson, VA, 23662
}

\begin{abstract}
The use of unmanned aircraft in the National Airspace System (NAS) has been characterized as the next great step forward in the evolution of civil aviation. Although use of unmanned aircraft systems (UAS) in military and public service operations is proliferating, civil use of UAS remains limited in the United States today. This report focuses on one particular regulatory challenge: classifying UAS to assign airworthiness standards. Classification is useful for ensuring that meaningful differences in design are accommodated by certification to different standards, and that aircraft with similar risk profiles are held to similar standards. This paper provides observations related to how the current regulations for classifying manned aircraft, based on dimensions of aircraft class and operational aircraft categories, could apply to UAS. This report finds that existing aircraft classes are well aligned with the types of UAS that currently exist; however, the operational categories are more difficult to align to proposed UAS use in the NAS. Specifically, the factors used to group manned aircraft into similar risk profiles do not necessarily capture all relevant UAS risks. UAS classification is investigated through gathering approaches to classification from a broad spectrum of organizations, and then identifying and evaluating the classification factors from these approaches. This initial investigation concludes that factors in addition to those currently used today to group manned aircraft for the purpose of assigning airworthiness standards will be needed to adequately capture risks associated with UAS and their operations.
\end{abstract}

\section{Nomenclature}

CFR = Code of Federal Regulations

CPA = Conventionally Piloted Aircraft

FAA $=$ Federal Aviation Administration

ICAO = International Civil Aviation Organization

NAS $\quad=$ National Airspace System

UAS = Unmanned Aircraft System

US = United States of America

\section{Introduction}

$\mathrm{T}$

HE use of unmanned aircraft in the National Airspace System (NAS) has been characterized as the next great step forward in the evolution of civil aviation. Despite significant progress made towards the goal of integrating unmanned aircraft systems (UAS) into the NAS ${ }^{1}$, numerous political, technological and regulatory challenges still

\footnotetext{
* Research Engineer, Safety Critical Avionics Systems Branch, m/s 130, Member, AIAA.

${ }^{\dagger}$ Research Engineer, Safety Critical Avionics Systems Branch, m/s 130.

* Research Engineer, Safety Critical Avionics Systems Branch, m/s 130, and Lifetime Associate Fellow, AIAA.

$\S$ President, Senior Member, AIAA.
} 
remain in realizing routine and safe operation of these aircraft ${ }^{2}$. One aspect of the regulatory challenge is to establish the airworthiness standards for UAS. Other organizations, especially militaries, have developed sets of airworthiness standards for their vehicles ${ }^{3}$. Such standards are helpful, but may not adequately address risks associated with civil operation in the NAS, or adequately "accommodate the diversity of UAS design, capability, and operations" ${ }^{4}$ expected for commercial applications. Indeed, as reported by Clothier, et al., "much effort is being devoted to the definition of standards specific to UAS (e.g., the specification of prescriptive requirements on aspects of their design, maintenance, manufacture and operation). However, little consideration has been given to how these standards and regulations may be appropriately applied across the diversity of UAS, their operations and the mitigation strategies widely employed.",

This paper examines the broad range of UAS by addressing one specific aspect of the airworthiness problem: namely, that of grouping similar UAS together for the purpose of assigning airworthiness standards, that is, UAS classification. Specifically this paper examines the classification problem through the perspective of using physical characteristics of the aircraft and its operational capabilities and limitations to place it in a group wherein all members would be assigned the same airworthiness standards. These characteristics and capabilities are referred to here as classification factors. This work leverages an initial survey of aircraft classification documented in Maddalon, et al. ${ }^{6}$

Classification of aircraft for the purpose of assigning airworthiness standards should account for hazards and their associated risks, in addition to accounting for substantive differences in design features. In this work, safety risk is the primary type of risk of interest, as opposed to other types of risk, such as economic risk or missionspecific risk. The FAA defines safety risk as the composite of predicted severity and likelihood of the potential effect of a hazard that could cause harm to persons or property damage. ${ }^{7}$ Ideally, if safety risks inherent in different types of UAS and their operations could be identified, then UAS classification could be fashioned around these identified risks. Although this is conceptually appealing, comprehensive risk identification across the spectrum of UAS has proven difficult. From a high-level perspective, DeGarmo made one of the best attempts ${ }^{2}$.

Instead of attempting to identify all risks across all types of UAS, the research approach described in this paper involved examining airworthiness classification approaches from a wide variety of organizations, and then identifying and evaluating the various factors used in these approaches. The classification system used for allocating airworthiness standards to civil manned aircraft by the Federal Aviation Administration (FAA) was examined first, followed by a survey of proposed classification approaches for UAS. Presumably, each organization, whether military or civilian, classifies aircraft to address the risks that they deem most relevant to safety, and, consequently, the factors that correspond to the risks deemed most important to safety. A basic hypothesis of this research is that the classification approach used for manned aircraft today is appropriate for UAS if the factors used to group manned aircraft are sufficient for grouping UAS for the purpose of assigning appropriate airworthiness standards. If those factors do not adequately capture either distinct design attributes of UAS or operational aspects that warrant different standards, then other factors should be considered. This analysis is both preliminary and subjective, especially due to the high degree of uncertainty in the specific hazards and risks associated with UAS operation in the NAS. The intent of this work is to offer preliminary observations to help guide further investigation, rather than precise conclusions. As additional hazard data is collected through increased operation of UAS, safety issues and risks can be better characterized and managed through appropriate classification.

Because classification of UAS is a regulatory topic, this research relies heavily on interpretation of the Federal Aviation Regulations, denoted in the rest of the paper as 14CFRX.Y**. This paper presents one view of the purpose and intent of the Federal Aviation Regulations with respect to airworthiness certification, and how those regulations may apply to UAS. It is not intended to be a complete or expert treatment of the subject. This paper should not be considered or used as an authoritative source for regulatory guidance, nor does it represent current or future US Government or FAA policy.

Before proceeding, a note on terminology may be helpful. Over the years, many terms have been used to describe unmanned aircraft; for example, drone, unmanned aerial vehicle (UAV), as well as unmanned aircraft system (UAS), which is the term this paper will use. A UAS is any aircraft without a pilot on board, including associated control station, communication links and ancillary equipment. Furthermore, this paper uses the term conventionally piloted aircraft or $\mathrm{CPA}^{8}$ to indicate an aircraft with a pilot on board.

This report is organized as follows. Section II outlines the scope of discussion on UAS classification and why classification of UAS is ultimately important to access to the NAS, and Section III defines terminology from the

\footnotetext{
** The notation 14CFRX.Y should be read as, "Title 14 of the Code of Federal Regulations, part X, section Y." This notation will be used throughout this paper when referring to specific regulations.
} 
regulations relevant to discussion of aircraft classification, and the fundamental structure and factors of the current aircraft classification for CPA. Section IV follows with a list of various factors taken from a survey of proposed UAS classification systems, for both civil use and public use, including approaches in both the US and other countries. Section V provides definitions for each factor. Section VI provides an analysis of each factor as it relates to some aspect of the risk of UAS.

\section{Airworthiness Motivation for Aircraft Classification}

According to 14CFR3.5, airworthy means that an aircraft "conforms to its type design and is in a condition for safe operation." One of the fundamental principles of Annex 8 of the International Civil Aviation Organization (ICAO) Chicago Convention states that a purpose of airworthiness is the "protection of other aircraft, third parties and property." In other words, a primary motivation for airworthiness is to preserve the safety of both participants and non-participants in the airspace. Airworthiness certification is one of several different certifications, required for an aircraft to operate legally in the NAS. 14CFR21 specifies the basic framework for civil certification procedures, including those for airworthiness, for aircraft products and parts in the United States.

According to 14CFR21.203, every civil aircraft that operates in the US must have a valid airworthiness certificate; and that certificate is issued when, among other things, the aircraft conforms to an approved type design (14CFR21.183). Thus, for an aircraft to operate in the NAS it must have an airworthiness certificate. Airworthiness standards reflect general consensus on minimum design and performance requirements necessary for safe flight; and are derived from engineering judgment and experience, especially lessons learned from accidents and incidents. But, an airworthiness certificate is not enough; all aircraft that operate in the NAS must actually be in an airworthy condition (14CFR91.7). ICAO Circular 328 makes it clear that UAS will be required to be airworthy and have a valid airworthiness certificate. ${ }^{8}$

Both standard and special airworthiness certifications exist for CPA. Under a standard airworthiness certificate, an aircraft typically has relatively few operating restrictions. Special airworthiness certificates include operational limitations such as restrictions on maneuvers, speed, number of passengers, activities undertaken, and where flights may be conducted. Clearly fewer operational restrictions are desired (from an operator's perspective); however, the cost of fewer operating restrictions is usually more stringent standards including levels of redundancy and fail-safe features to meet reliability requirements. Most commercial CPA operations require a standard airworthiness certificate. Presumably, UAS could use the same two types of airworthiness certifications.

The certification framework for CPA has evolved over time along with the aircraft industry itself, and is a contributing factor to the overall safety of the NAS. Clothier, et al. observe, "A prerequisite to the realization of a viable civil UAS industry is the definition of an appropriate airworthiness certification framework for UAS. This framework must take into consideration the unique aspects of the technology, their operations, the market drivers, and the broader socio-political issues associated with the integration of a new aviation technology into society." Developing a regulatory system for UAS has proven to be quite challenging because the safety argument that underlies standards for CPA differs for unmanned aircraft in several fundamental aspects, including the separation of the aircraft itself from the pilot station, and the ability to see and avoid with the human eye. These points are confounded by the extensive range of UAS types.

A key issue related to the development of airworthiness standards for civil UAS, and a primary focus of this paper, is that of aircraft classification for airworthiness. Classification, as used in civil certification, partitions aircraft with their operation into groups for the purpose of assigning regulations, requirements, standards or other guidance to the aircraft within each group. Several motivations for classification are identified, including:

1. Aircraft that pose different hazards require different standards

2. Efficiencies through the use of standards, versus case-by-case

3. Operational risk balancing

4. Certification risk compensation

Each of these motivations is described below along with its potential applicability to a UAS classification approach.

Classification provides a means for grouping aircraft together with similar design, especially aerodynamic attributes, for example rotorcraft or fixed wing aircraft. Since different groups of aircraft differ in meaningful ways, especially with respect to the hazards they pose to the NAS, different standards should be applied to them. Classification enables those differences to be recognized in a straight-forward manner. Classification of UAS could proceed in a similar way: UAS accomplish critical functions in different ways that, perhaps, will be subject to different standards. For example, the "sense and avoid" capability may be provided through an on-board system or it may be provided through a ground-based system. Although the safety objective - to sense and avoid air traffic- 
is the same for either approach; the airworthiness standards may vary quite a bit depending on how the function is accomplished. Conceivably, other differences can be handled in similar ways.

There is a compelling practical effect of classification: efficiency in certification. Classification allows the development of detailed standards which can be applied to different aircraft classes. 14CFR includes standards such as: specific design criteria (e.g., structural load limits), required design features (e.g., existence of fire extinguishers), and performance parameters (e.g., required ratios of rotation speed to minimum control speed). An applicant for certification establishes their product's regulatory requirements in collaboration with the certification authority. These requirements are based on the existing standards and also include agreement on deviations from the standard to account for specific design elements of their aircraft. ${ }^{10}$ Benefits of standards-based certification include a priori knowledge of the expectations for certification, which facilitates planning from a design and cost perspective for certification, as well as providing a consistent and level playing field for all applicants. The use of the preestablished standards is not required, however. An applicant could use the approach in 14CFR21.17b for a unique design. This approach is much more labor-intensive for both the applicant and the certifying authority, with much more uncertainty in the outcome.

Classification also supports operational risk balancing. Many operations of CPA have critical safety risks, such as flight with passengers on board, flight over populated areas, etc. These operations require high assurance of safe conduct of flight and necessitate levels of redundancy and fail-safe features to meet reliability requirements. Other operations that pose a lower safety risk are held to a lower standard. One means provided in 14CFR to perform this risk tradeoff is through certification under a restricted aircraft category, where the operation of a restricted category aircraft is limited to special purposes identified in their type certification approval. This category is used for limited special purpose operations in manned aviation today, e.g., agricultural spraying and aerial surveying. For UAS, this classification could be applied in a straightforward manner. For instance, one can imagine that an agricultural UAS could fly under operational restrictions similar to conventionally piloted agricultural aircraft.

Finally, classification supports risk reduction through the notion of certification compensation. The FAA issues publications, including advisory circulars, to provide guidance to industry on compliance with the requirements in 14CFR. Advisory Circular (AC) 23.1309 describes how certification standards are lowered for avionics for some general aviation airplanes. ${ }^{11}$ The assessment is made that low-time general aviation pilots have made mistakes that might have been prevented with advanced avionics, and therefore the avionics certification requirements (and associated costs) are lowered to encourage greater equipage. Essentially, regulators concluded that the risk of a lowtime general aviation pilot making a mistake is greater than the risk of the avionics misbehaving. The operational risk is mitigated through acceptance of an airworthiness risk, and by this assessment overall system risk is lowered. Since all current UAS have no people on board, some have suggested that this certification compensation notion should apply to UAS as well. This suggestion is controversial because the many differences that exist between conventionally piloted aircraft and UAS make it unclear how certification standards may be relaxed.

\section{Classification of CPA for Airworthiness in 14CFR}

The research investigation of possible classification of UAS for airworthiness started with an analysis of the existing certification framework for CPA. The classification approach in 14CFR has evolved over several decades to accommodate the introduction of new aircraft types and as real-world issues-including technical, economic, and political issues - needed to be resolved. For this effort, 14CFR was used as the primary source for defining the existing classification system and determining the underlying classification factors.

The classification structure provided in 14CFR distinguishes between an aircraft's physical characteristics, called aircraft class, and an aircraft's intended use or operating limits, called aircraft category. Specifically, as defined in 14CFR1.1, aircraft class "means a broad grouping of aircraft having similar characteristics of propulsion, flight, or landing. Examples include: airplane; rotorcraft; glider; balloon; landplane; and seaplane." Also in 14CFR1.1, aircraft category "means a grouping of aircraft based upon intended use or operating limitations. Examples include: transport, normal, utility, acrobatic, limited, restricted, and provisional." 14CFR does not specifically define the word classification. In this paper, the term classification means any grouping of aircraft and their operations, which is consistent with its use in the CFR. Type design criteria are typically applied to the class and category pair; for example, a fixed wing aircraft (airplane class) regularly transporting more than 50 passengers (transport category), commonly called a transport category airplane, has its type design criteria captured in 14CFR25 (i.e., "Part 25").

Of particular note, weight is a key factor in CPA classification. This physical parameter can be viewed as a proxy for safety-related risk, that is, heavier aircraft pose a greater risk to occupants on board the aircraft and to others in the airspace and therefore have more stringent airworthiness standards. However, aircraft classification for airworthiness standards in 14CFR includes considerations beyond aircraft weight. This section discusses some of 
the most relevant considerations, as they may affect the inclusion of UAS within that framework. A more extensive summary of the classification system in 14CFR is presented in a related technical report. ${ }^{6}$

\section{A. Aircraft Class}

14CFR1.1 lists the following examples of aircraft classes, based on flight, propulsion, and landing characteristics: airplane (i.e., fixed wing), rotorcraft, glider, balloon or manned free balloon, landplane, and seaplane. Determining whether an aircraft is in one of these classes is fairly straightforward. For example, if an aircraft gets its aerodynamic lift from rotating blades, including gyroplanes, the aircraft is a rotorcraft. For aircraft outside of these classes, such as a tilt-rotor, certification would be handled under the special provisions of 14CFR21.17b. Presumably, if the market for tilt-rotors grows and the FAA certifies several of them, then tilt-rotor could become an aircraft class with corresponding standards for that class of aircraft.

Most UAS designs fit well within the aircraft classes listed above. Unmanned Vehicle Systems International (UVSI) provides an annual yearbook that catalogs UAS throughout the world from many domains including law enforcement, commercial, military, research, etc. According to UVSI's 2012 yearbook, of the 1103 vehicles surveyed only 23 would not fit into one of the existing aircraft classes. ${ }^{12}$ Those that do not fit include novel configurations such as flapping wings or tilt body aircraft.

\section{B. Aircraft Category}

The aircraft categories in 14CFR, where the groupings are primarily based on similar use or operating limitations, are provided in Table 1. This table shows the relationship among aircraft category, airworthiness certificates, and the possibility of performing the operation for "compensation or hire," that is, to be paid for the operation.

Table 1. Relationship of Airworthiness Certification and Use for Compensation to Aircraft Categories

\begin{tabular}{|c|c|c|}
\hline Category & $\begin{array}{c}\text { Airworthiness } \\
\text { Certificate }\end{array}$ & $\begin{array}{c}\text { Compensation } \\
\text { or Hire }\end{array}$ \\
\hline Normal & Standard & Yes \\
\hline Acrobatic & Standard & Yes \\
\hline Utility & Standard & Yes \\
\hline Commuter & Standard & Yes \\
\hline Transport & Standard & Yes \\
\hline Restricted & Special & Yes \\
\hline Primary & Special & No \\
\hline Limited & Special & No \\
\hline Light-sport $^{\text {ti }}$ & Special & No \\
\hline Experimental $^{\S}$ & Special & No \\
\hline Provisional $^{\S}$ & Special & No \\
\hline
\end{tabular}

As seen in Table 1, most paid operations require a standard airworthiness certificate. Under a standard airworthiness certificate, an aircraft typically has few operating restrictions, beyond the flight rules captured in 14CFR91, 14CFR121, etc. Special airworthiness certificates include operational limitations such as restrictions on maneuvers, speed, number of passengers, activities undertaken, and where flights may be conducted. As per 14CFR21.183, standard airworthiness certificates might also be issued to aircraft that are not in a category, specifically manned free balloons (14CFR31), or aircraft designated as special classes of aircraft (gliders, airships, etc.).

The next step in understanding aircraft classification under 14CFR is to examine how the aircraft categories themselves are defined. Because the focus of this paper is on certification for civil operations, especially flights for compensation or hire, the discussion here focuses on categories that operate under a standard airworthiness certificate, and the restricted category for special purpose operations. Table 2 relates aircraft categories to the

\footnotetext{
† Only some operations are allowed for compensation, such as for agriculture or aerial surveying (14CFR21.25)

$\$$ A short list of World War II era aircraft have limited category type certificates [FAA-8130.2G]

$\S \S$ The provisional category is used during the development of an aircraft in some other category, but the vehicle in question has not met all the requirements for a type certificate and/or standard airworthiness certificate.
} 
primary 14CFR part containing applicable airworthiness standards per aircraft class that would typically serve as the type certification basis under a standard airworthiness certificate or special airworthiness certificate-restricted category. The third column presents the expected starting point for type design criteria. This table is not intended to include everything in a typical certification basis, such as noise regulations specific to equipage for operational capabilities found in other parts of 14CFR.

Table 2. Current Aircraft Category and Regulatory Basis Supporting Type Certification ${ }^{6}$

\begin{tabular}{|c|c|c|}
\hline $\begin{array}{l}\text { Aircraft } \\
\text { Category }\end{array}$ & Aircraft Use and Notable Limitations & $\begin{array}{l}\text { Applicable Airworthiness } \\
\text { Standards for Type Design }\end{array}$ \\
\hline Acrobatic & $\begin{array}{l}\text { Use: acrobatics } \\
\text { Notable limitations: } \\
\text { weight } \leq 12,500 \mathrm{lbs} \text {. } \\
\text { seats } \leq 9 \text {, excluding pilot seats, (14CFR23.3) }\end{array}$ & $\begin{array}{l}\text { 14CFR23, with regulations } \\
\text { specific to acrobatic category } \\
\text { airplanes } \\
\text { No acrobatic rotorcraft } \\
\end{array}$ \\
\hline Normal & $\begin{array}{l}\text { Use: flights that are not acrobatic, utility, or commuter } \\
\text { Notable limitations: } \\
\text { weight } \leq 12,500 \text { lbs. (airplanes), } \leq 7000 \text { lbs. (rotorcraft) } \\
\text { seats } \leq 9 \text {, excluding pilot seats (14CFR } 23.3 \text { ) }\end{array}$ & \begin{tabular}{|l|} 
14CFR23 for airplanes \\
14CFR27 for rotorcraft
\end{tabular} \\
\hline Utility & $\begin{array}{l}\text { Use: normal + limited acrobatics allowed; e.g., spins } \\
\text { (14CFR23.3) } \\
\text { Notable limitations: } \\
\text { weight } \leq 12,500 \text { lbs. } \\
\text { seats } \leq 9 \text {, excluding pilot seats }\end{array}$ & $\begin{array}{l}\text { 14CFR23 for airplanes } \\
\text { No utility rotorcraft }\end{array}$ \\
\hline Commuter & $\begin{array}{l}\text { Use: commuter operations (scheduled operation with at } \\
\text { least } 5 \text { round trips/week on at least one route between two } \\
\text { or more points according to the published flight schedules } \\
(14 \text { CFR110.2)) } \\
\text { Notable limitations: } \\
\text { weight } \leq 19,000 \text { lbs. } \\
\text { seats } \leq 19 \text {, excluding pilot seats (14CFR23.3) }\end{array}$ & $\begin{array}{l}\text { 14CFR23 for airplanes } \\
\text { No commuter rotorcraft }\end{array}$ \\
\hline Transport & $\begin{array}{l}\text { Use: multi-engine aircraft intended for the regular public } \\
\text { transport of passengers and/or cargo for hire or reward } \\
\text { Notable limitations: } \\
\text { weight: }>19,000 \text { lbs. (jets \& props), 7,000 lbs. (rotorcraft) } \\
\text { seats } \geq 10 \text { (jets), seats }>19 \text { (props and rotorcraft) }\end{array}$ & $\begin{array}{l}\text { 14CFR25 for airplanes } \\
\text { 14CFR29 for rotorcraft }\end{array}$ \\
\hline Restricted & $\begin{array}{l}\text { Use: special purpose operations (as defined in 14CFR21.25, } \\
\text { including agriculture and aerial surveying) } \\
\text { Notable limitations: no operation over densely populated } \\
\text { areas, in a congested airway, or near a busy airport } \\
\text { (14CFR91.313) }\end{array}$ & $\begin{array}{l}\text { Requirements of some other } \\
\text { category or an aircraft meeting the } \\
\text { requirements and accepted for use } \\
\text { by the US military with } \\
\text { exemptions and operating } \\
\text { limitations specific to the special } \\
\text { purpose (14CFR21.25) }\end{array}$ \\
\hline
\end{tabular}

As shown in this table, categories are defined in terms of aircraft weight, but also other factors such as number of seats, maneuverability (acrobatic maneuvers), number of engines, frequency of flights, and public transport of passengers or cargo. It is not difficult to recognize how each of these factors affects risk to the people on-board those aircraft.

Unlike the aircraft classes described in subsection A, the direct applicability to UAS of the aircraft categories and the factors used to distinguish them is debatable. For example, the intended uses for UAS do not necessarily align as well with the existing set of aircraft categories. Although one can imagine transport category UAS for cargo, notions of normal, acrobatic, and utility category UAS are not so clear. Little, if any, data exists to show how factors such as maneuverability, number of engines, and number of scheduled operations affect risk for UAS. This observation points to a conclusion that the utility of applying the current classification system to UAS is unknown. From this, it seems reasonable to posit a modified or alternative classification system with additional aircraft categories and factors which enable the differentiation of risk between UAS platforms. 


\section{System Certification}

Partitioning of aircraft into groups in the current regulations does not end with a discussion of class and category. Requirements specified in other guidance documents, such as FAA Advisory Circulars, provide additional criteria for grouping aircraft with respect to one or more airworthiness requirements. One particular requirement, 14CFR23.1309, regulates equipment, systems, and installations on-board normal, acrobatic, utility, and commuter category airplanes. The accompanying advisory circular (AC23.1309-1E), System Safety Analysis and Assessment for Part 23 Airplanes ${ }^{11}$, which describes a means to meet the regulation, specifies four "certification classes of airplanes" within Part 23. This use of the term class has no relationship to the term described in subsection A.

Table 3. Influence of Weight and Engines on Classification from AC23.1309-1E

\begin{tabular}{|l|l|l|}
\hline Class I & Normal, Utility, or Acrobatic Category & Commuter Category \\
\hline Class II & $\begin{array}{l}\text { Weight } \leq 6000 \text { lbs. } \\
\text { Single reciprocating engine } \\
\text { Either multiple reciprocating engine or a } \leq 6000 \text { lbs. } \\
\text { turbine engine }\end{array}$ & N/A \\
\hline Class III & $\begin{array}{l}\text { Weight }>6000 \text { lbs. } \\
\text { Either a multiple reciprocating engine or } \\
\text { a turbine engine }\end{array}$ & N/A \\
\hline Class IV & N/A & $\begin{array}{l}\text { Weight } \leq 19,000 \mathrm{lbs} . \\
19 \text { or fewer seats }\end{array}$ \\
\hline
\end{tabular}

AC23.1309-1E assigns specific reliability and design assurance requirements to each of these classes, which affects system design and development cost. The important point with respect to UAS classification is that both airplane weight, and number and type of engines are factors that ultimately affect how aircraft are grouped together with respect to type design criteria.

Based on the data in Tables 2 and 3, Table 4 presents the primary factors that underlie the classification of CPA with respect to airworthiness standards.

Table 4. Primary Airworthiness Classification Factors from 14CFR

\begin{tabular}{|l|l|}
\hline Weight & Scheduled operations \\
Number and type of engines & Frequency of operations \\
Maneuverability & Motivation for use \\
Number of passenger seats & Responsible party \\
\hline
\end{tabular}

\section{Survey of Classification Factors for Unmanned Aircraft}

In the last few years, many governmental, research, and private organizations throughout the world have examined the issue of UAS classification. In a related technical report, an extensive survey of UAS classification approaches encompassing 22 organizations from 15 countries was conducted. ${ }^{6}$ The classification approaches identified in this survey are proposed or used in assigning regulations, requirements, standards or other guidance for UAS to operate in civil and public use environments. Some organizations have classification approaches specific to airworthiness (that is, grouping together different UAS for the purpose of assigning airworthiness requirements), while other organizations have only specified operational limitations. Still others propose some combination of the two. As such, there are a variety of factors used for classifying UAS in each context. It is notable that organizations in this survey did not explicitly mimic the approach in 14CFR; however, many organizations included both aircraft factors and operational factors, somewhat similar to the class/category approach in 14CFR.

Table 5 provides a high-level summary of the classification factors identified from the various UAS classification approaches given in the survey. As shown in the table, some organizations only use one factor whereas other organizations use two or three different aircraft or operational characteristics together to distinguish different groups of UAS. 
Table 5. Pertinent Factors and Combinations for Potential Use in UAS Classification ${ }^{6}$

\begin{tabular}{|l|l|}
\hline $\begin{array}{c}\text { Number of } \\
\text { Factors }\end{array}$ & Combinations of Classification Factors for UAS \\
\hline \multirow{4}{*}{ One } & Aircraft weight \\
\cline { 2 - 3 } & Avionics complexity \\
\cline { 2 - 3 } & $\begin{array}{l}\text { Aircraft configuration: airplane (including number and type of } \\
\text { engines), rotorcraft, etc. }\end{array}$ \\
\hline \multirow{5}{*}{ Two } & Aircraft weight, and Airspeed \\
\cline { 2 - 3 } & Aircraft weight, and Motivation for operation \\
\cline { 2 - 3 } & Aircraft weight, and Operational range \\
\cline { 2 - 3 } & Airspace (segregated, non-segregated), and Overflown area \\
\cline { 2 - 3 } & Kinetic energy, and Overflown area \\
\cline { 2 - 3 } & Kinetic energy, and Operational range \\
\cline { 2 - 3 } & Kinetic energy, and Operational failure consequence \\
\hline \multirow{5}{*}{ Three } & Aircraft weight, Altitude, and Operational range \\
\cline { 2 - 3 } & Aircraft weight, Airspeed, and Frangibility \\
\cline { 2 - 3 } & Aircraft weight, Kinetic energy, and Operational range \\
\cline { 2 - 3 } & Aircraft weight, Altitude, and Application \\
\cline { 2 - 3 } & Aircraft weight, Altitude, and Airspeed \\
\hline
\end{tabular}

Although there are a number of different combinations of factors listed in Table 5, two observations are apparent. First, aircraft weight, either directly or through kinetic energy (a combination of weight and speed), is the predominant factor influencing safety risk in UAS operations. Second, operational aspects are also considered an important driver for risk in many of the classifications. These operational aspects are different from those shown in Table 2. For example, operational factors that affect risk for UAS include if the operation is conducted within visual range or if the operation is over a populated area. This particular observation is important because such operational aspects are not always a factor in the existing classification for CPA. Aircraft weight is the dominant factor affecting risk for CPA operating under a standard airworthiness certificate-where the aircraft operates is inconsequential from a risk perspective compared with the risk to the people on-board. This is reflected in the fact that normal, acrobatic, utility, commuter, and transport aircraft are not distinguished by where they fly, but largely by weight. Generally speaking, heavier aircraft allow more people to be carried, and thus must meet more stringent reliability requirements. Under a special airworthiness certificate-restricted category, where the aircraft operates is an important factor. Because operation of those aircraft is in a limited operational area, operational restrictions can compensate for not meeting all airworthiness standards expected under a standard certificate. The fact that many of the proposed UAS classification approaches include operational dimensions may suggest that further exploration of operation under a restricted category is warranted.

\section{Candidate Factors for UAS Classification}

In this section classification factors identified from three sources (the existing classification system for CPA provided in the CFR, a survey of UAS classification factors ${ }^{6}$, and additional factors that the authors of this paper consider worthy of consideration) are more formally described to support analysis of how each factor may, or may not, influence the classification of UAS. The source documents for these factors did not typically include a detailed explanation for each factor. So, as part of the elaboration process, an explanation and description of the factor is proposed to cover both the assumed intent from the original source document, plus additional considerations from the wider UAS design space. The factors considered in this analysis are summarized in Table 6 along two dimensions, first by the aggregate source of where the factor was identified and second by how the factor will be established: primarily by the design of the aircraft or by the operation of the aircraft.

A short description of each factor is provided below. Not all factor descriptions are equal; that is, some are technical, some socio-technical; and some are simple, and some are very complex. For factors used for CPA classification, the description includes a high-level analysis of the applicability of each factor to UAS. The aircraft factors are described first, followed by the operational factors. 
Table 6. Summary of All Candidate Factors for UAS Classification

\begin{tabular}{|c|l|l|}
\hline \multicolumn{1}{|c|}{ Aircraft Factors } & \multicolumn{1}{c|}{ Operational Factors } \\
\hline $\begin{array}{c}\text { Factors identified } \\
\text { from the existing } \\
\text { CPA classification } \\
\text { framework in } \\
\text { 14CFR }\end{array}$ & $\begin{array}{l}\text { Weight } \\
\text { Number and type of engines } \\
\text { Maneuverability } \\
\text { Number of passenger seats }\end{array}$ & $\begin{array}{l}\text { Scheduled operations } \\
\text { Frequency of operations } \\
\text { Motivation for use } \\
\text { Responsible party }\end{array}$ \\
\hline $\begin{array}{c}\text { Factors identified } \\
\text { from the survey of } \\
\text { UAS }\end{array}$ & $\begin{array}{l}\text { Avionics complexity } \\
\text { Airspeed } \\
\text { Kinetic energy } \\
\text { Opsifications }\end{array}$ & $\begin{array}{l}\text { Operational area } \\
\text { Overflown area } \\
\text { Operational failure consequence } \\
\text { Altitude }\end{array}$ \\
\hline Additional Factors & Cost & Flight time \\
\hline
\end{tabular}

Weight

The maximum takeoff weight is the maximum weight the pilot of the aircraft is allowed to attempt to take off due to structural or other limits. 14CFR recognizes that weight has both static and dynamic interactions with the aircraft structure and directly and indirectly influences controllability and performance characteristics to help maintain safety of flight. Generally speaking, heavier aircraft carry more people (or more cargo) and any adverse event on the aircraft will have a greater severity. In that sense, weight correlates positively with safety risk, particularly with respect to hazard severity. As such, weight is the primary factor used in defining a number of distinctions in aircraft classification, such as commuter category from transport, normal/utility/acrobatic from commuter, and Class I \& II from AC23.1309 from Class III. Due to lightweight materials and advances in technology, the FAA Part 23 Small Airplane Certification Process Study ${ }^{13}$ argues that original weight assumptions (and inferred risks) are no longer valid differentiators for determining airworthiness requirements. This observation from the Part 23 study may also apply to UAS designs.

\section{Number and type of engines and propellers}

14CFR23 distinguishes aircraft performance, stability, and controllability requirements based on the number of engines along with their type, either piston or turbine, usually in combination with other factors, such as weight. In a similar way, AC23.1309-1E partitions aircraft partially based on the number and type of engines and assigns reliability and design assurance requirements based on this partitioning. This factor could be used in similar ways for UAS; however, the wide range of UAS designs and operational needs may stress this factor in new ways. For instance, many UAS will be electrically driven, possibly with solar power or fuel cells as sources for electrical power, whereas other UAS may use hydrogen power sources. "Multi-engine" for a UAS could mean 10 or more engines in some long endurance designs.

\section{Maneuverability}

Maneuverability is an amalgam of a number of performance parameters including performance, controllability, stability, trim, stall, and spin characteristics. In 14CFR23, maneuverability, as it relates to structural loading and spin characteristics, is used partly to distinguish between the normal, utility, and acrobatic categories. While maneuverability is not used to otherwise partition aircraft, the requirements for maneuverability may differ in groups partitioned by other factors, such as weight, altitude, speed, or number/type of engines. It is reasonable to assume that UAS will need to maintain some minimum level of maneuverability; however it is unclear whether the current maneuverability specifications for normal, utility, and acrobatic aircraft are appropriate for UAS or whether maneuverability requirements should be used to partition UAS for other reasons, such as the ability to meet minimum standards to avoid other air traffic.

\section{Number of passenger seats}

The number of passenger seats is a proxy for the potential number of people on board an aircraft. It can be inferred that as the number of passenger seats (and hence passengers) increase, overall safety risk increases, and 
hence more stringent airworthiness requirements must be satisfied to mitigate that risk. In some ways this factor is closely related to the weight factor since as more passengers are carried, more weight is carried. Because the number of passenger seats would only be relevant to a UAS that has passengers, this factor is not currently applicable to UAS since passenger-carrying UAS are only considered for the far-term.

\section{Avionics complexity}

Complexity is a topic of frequent discussion in the avionics community, and particularly difficult to precisely define. For this study, an avionics system is considered complex "when its operation, failure modes, or failure effects are difficult to comprehend without the aid of analytical methods or structured assessment methods." 11 Examples of structured assessment methods include Failure Modes and Effects Analysis and Fault Tree Analysis. According to the definition above, a complex system is one in which its behavior, especially in fault scenarios, is not apparent. This lack of transparency may lead to concerns about unintended or unpredicted behavior, and consequently may require more stringent reliability and design assurance levels to mitigate that risk. The factor may not be straightforward to apply to UAS.

\section{Airspeed}

Airspeed is the velocity of an aircraft relative to the air mass through which it is flying. Airspeed operating limitations revolve around flying at the velocity that results in the desired performance to ensure safe flight. In general, violations to airspeed limitations would impede safe landings for CPA. Airspeed limitations minimize impact to other airborne objects and to people/property on the ground. Airspeed is not one of the factors identified for partitioning CPA, but was used in some UAS classifications found in the survey. Airspeed affects UAS operations in a similar way to existing manned operations. However, design considerations with respect to UAS airspeed may be substantially different from CPA and thus require different minimum design standards, considering the expanded operating envelop for many UAS.

\section{Kinetic energy}

Kinetic energy is a factor unique to some of the UAS classifications in the survey. Kinetic energy is defined as the product of an aircraft's maximum mass $(m)$, one half, and the square of its maximum speed $(v)$, i.e., $1 / 2 m v^{2}$. Because kinetic energy can be viewed as the work which is required to stop a body in motion, kinetic energy is a proxy for the amount of damage that can be inflicted on impact. So, kinetic energy is important to safety risk for UAS, in the sense that safety is interested in potential harm to persons, as well as to property.

\section{Operational range}

Operational range is defined as the distance between the control station and the aircraft. This factor is unique to UAS. Operational range may be expressed numerically as a distance or qualitatively as "Line-of-Sight" or "Beyond Line-of-Sight." ICAO Circular 328 further distinguishes between visual line-of-sight and radio line-of-sight. ${ }^{8}$ The distinction between visual and radio points to two distinct hazards: visual line-of-sight operations allow a human to provide "see and avoid" capability and radio line-of-sight recognizes a UAS may lose radio contact and potentially becoming uncontrolled by any human. A UAS with a beyond-radio-line-of-sight capability will have a complicated communication system (perhaps involving satellites or multiple ground-based communication relays) or it will be capable of full operation without human intervention (i.e., autonomous operation).

\section{Frangibility}

Frangibility means to break into pieces or the nature of breaking into pieces in order to mitigate the consequences of collision or impact. This factor, like operational range, is unique to UAS. Frangibility relates to the ability of a material or structure to absorb energy thus minimizing injury. In general, frangibility implies the consequence (severity) of a collision between a UAS and another aircraft or person/property can be reduced due to the frangibility of all or part of the UAS component or design. Some organizations consider that a frangible UAS may proceed with a lower level of robustness due to its lower risk to people and other aircraft. 


\section{Scheduled operations}

In 14CFR110.2, a scheduled operation is defined as "any common carriage passenger-carrying operation for compensation or hire conducted by an air carrier or commercial operator for which the certificate holder or its representative offers in advance the departure location, departure time, and arrival location. It does not include any passenger-carrying operation that is conducted as a public charter operation." Key points relevant to classification are that a scheduled operation is passenger carrying, for compensation/hire, by a certificate holder (i.e., air carrier), with advance knowledge of schedule/location. This factor, coupled with frequency of operations, contributes to the partitioning of commuter category from normal flying from an operational perspective. By itself, the fact that an operation is scheduled does not seem to have a significant effect on airworthiness standards, especially reliability and design assurance requirements. There are two challenges with this factor as applied to UAS. First, near-term UAS will not carry passengers and second, it is not clear if the business case for UAS will typically involve published schedule information. Leaving aside these issues, a UAS performing a scheduled operation may present a similar risk to a CPA performing a scheduled operation.

\section{Frequency of operations}

Frequency of operations is simply the number of times that an aircraft completes its intended operation, often measured on a weekly basis. For example, commuter operations are defined as operations of at least five round trips per week. A key point is that this factor accounts in some sense for the risk of an accident on takeoff and landing. A manned aircraft is more likely to crash on takeoff and landing, than in any other phase of flight; so, the more frequent the operations, the higher the standards. For UAS, it is not clear that takeoff and landing necessarily represent the most risky phases of flight. Loss of control, which is a significant hazard for UAS, may be more prevalent during en-route or loitering phases of flight.

\section{Motivation for use}

Motivation for use is a factor that describes, at varying levels, the purpose of operating an aircraft. To a large extent, this factor distinguishes between private use (e.g., recreation) and operation of the aircraft for compensation for CPA. It should be noted that not all operations by a company are considered compensated operations. Generally, if a flight operation is incidental to the business, then it is considered a private operation. Private versus compensated use is not the only distinction in CPA classification, though. 14CFR21.25 lists a number of specific special purpose operations that can be conducted for compensation under a special airworthiness certificaterestricted category, including agricultural (spraying, dusting, seeding, and livestock and predatory animal control); forest and wildlife conservation; aerial surveying (photography, mapping, and oil and mineral exploration); patrolling (pipe lines, power lines, and canals); weather control (cloud seeding); and aerial advertising (skywriting, banner towing, airborne signs, and public address systems). Overall, motivation for use affects airworthiness standards for CPA in the sense that standards are higher when the motivation for use is compensation or hire, versus personal or recreational use. Operation under a restricted category for compensation may allow for some standards to be relaxed in lieu of operational limitations. The same reasoning seems generally applicable to UAS.

\section{Responsible party}

The responsible party is the person or organization responsible for the safe operation of the flight. In some ways this is a further refinement of commercial operation. A primary distinction with respect to regulation is whether the operator is a commercial operating certificate holder, who is allowed to operate an aircraft for compensation or hire. With respect to classification, this factor is similar to motivation for use (see above) with respect to whether the benefit of the flight is personal or private versus commercial transportation (for compensation or not). Generally speaking, airworthiness standards are higher when services are compensated, versus when they are not (volunteer, personal/corporate use). The same reasoning seems generally applicable to UAS.

\section{Operational area}

Operational area groups UAS based on the type of airspace where these UAS normally conduct their operation. In its most basic form, the airspace types include areas where only UAS are allowed (i.e., "segregated") and areas where UAS mix with CPA (i.e., "non-segregated"). One can envision this factor using finer distinctions of airspace 
types, such as the airspace classes A, B, C, etc. Operational area is not used for partitioning CPA, but can be used to limit operations for restricted-category certifications or other purposes (e.g., temporary flight restrictions). To the extent that the operational area factor relates to the exposure, duration, or consequences of risk to other parties (in the air or on the ground) it may be a good proxy for risk. This factor does not represent a restriction on airspace usage for UAS. Rather, it defines categories with more and less stringent airworthiness standards.

\section{Overflown area}

Similar to operational area, overflown area partitions UAS based on, nominally, what is underneath them when they conduct their normal operation. The overflown area is typically categorized based on some notion of population density. At its most basic level, the categories are populated and unpopulated. This factor is not used for partitioning CPA, although it may be a good proxy for risk to humans and/or objects on the ground in that it relates directly to consequences, exposure, and duration of risks. In that sense, overflown area may be an important factor for UAS classification. Like operational area, this factor does not represent a restriction on the areas overflown by a UAS. Rather, it defines categories with more and less stringent airworthiness standards.

\section{Operational failure consequence}

Operational failure consequence attempts to capture the notion that eventually a UAS will have a failure and this failure may have significant consequences. Many other factors use a generalized notion of avoiding hazards; this factor identifies the hazards to be addressed. In particular, the European Aviation Safety Agency (EASA) partitions UAS for certification purposes relative to two specific hazards ${ }^{14}:$ (1) loss of thrust leading to impact with the ground, i.e., "unpremeditated descent;" and (2) loss of control, under powered flight, resulting in impact with the ground. To assign consequence, EASA uses the aircraft's associated kinetic energy associated with those two events to assign airworthiness requirements.

\section{Altitude}

Altitude is used in two slightly different ways in various UAS classification schemes: as the maximum altitude for a UAS operation, and as the normal operating altitude for the UAS. There are multiple ways that altitude is used in 14CFR, including height above mean sea level, height above the terrain, pressure altitude, and cabin pressure altitude. Cabin pressure altitude is irrelevant to a UAS without people on board. For UAS, altitude could be used in a number of ways. For example, small UAS may be restricted to operate below 400 feet, which provides segregation from other air traffic, since 14CFR91.119 states that aircraft should fly at least 500 feet above any obstructions in uncongested areas (1000 feet in congested areas). In addition altitude could be used to ensure that UAS do not enter class A airspace. Finally, another way that altitude could be used in classification is the notion of danger to the ground. If a vehicle is high in the air, and loses control from the pilot, then the vehicle may glide a long way (perhaps 100's of miles) before it hits the ground. This distance may be outside of operating restrictions. For instance, a vehicle operating over cornfields at a high altitude, in such a failure condition, could fly to a city.

\section{Flight time}

Flight time is the maximum time the aircraft can stay aloft without an operational intervention, such as refueling. This factor tries to capture a notion of endurance, that is, how long a UAS can fly "on its own." Since UAS platforms need not land and take off with the frequency dictated by piloted vehicles (as pilots can remain in the air no longer than the times specified in 14CFR91.1057, 14CFR91.1059-1062), maximum flight time performs a similar function as frequency of flights might in a commercial airline operation.

\section{Aircraft cost}

The use of aircraft cost has no precedent in the regulation or classification of CPA. As such, its use may be controversial; although this factor is proposed because it captures a unique aspect of risk: the risk borne by a UAS's owners. Such costs are not traditionally the concern of regulatory authorities. But, cost is worth mentioning here because aircraft cost can greatly influence the strategies employed for aircraft design for potential loss events. If the aircraft is designed to be retrieved after a mission, loss of control mitigation strategies will attempt to mitigate first, second and third party risk. If the aircraft is not reusable, then only second and third party risk need be considered in 
mitigation strategies. As the cost of the aircraft increases in relationship to the limited liability the aircraft incurs with respect to second and third parties, the mitigation strategies will shift to preserving aircraft integrity over preventing overall damage caused to other parties. Thus, if an aircraft is designed to be deployed in unpopulated areas, secondary and third party risks may be minimal compared to cost incurred by the loss of the aircraft or its mission data.

Several definitions of aircraft cost may be used including: capital asset value and revenue generation value. Capital asset value may be its current value (purchase price minus depreciation) or may be its initial value. The revenue generation value recognizes that if the aircraft is lost, the owner may have to forego revenue until a replacement can be fielded. Each of these costs has significant issues that must be addressed such as is the ground station included in the cost, accounting issues, time value of money, etc.

\section{Analysis of Factors}

Analysis of these factors proceeds with assessing how each factor relates to different aspects of safety risk of UAS. Although this analysis is qualitative and arguably speculative, it provides useful general insights. This analysis considers four aspects relevant to safety risk: likelihood and severity (the conventional components of safety risk), and also duration and expectation. Likelihood refers to the probability that a hazardous event will happen; the higher the likelihood, the higher the risk, assuming all other factors are equal. Severity refers to how bad the consequence of a safety event might be; the more severe the effect of an event, the higher the risk, assuming the same likelihood. Duration refers to the length of time during which a hazardous event could occur. In general, shorter duration times are desirable. Although duration may be captured as part of likelihood, duration was considered explicitly in this analysis because time associated with some UAS operations, and hence exposure time for hazards and risk, is significantly different from CPA. Finally, expectation refers to a notion of a relative level of acceptable risk. For example, in manned aviation, compensated operations have a higher expectation of safety than private or personal operations. This expectation, though subtle, may influence severity, and may be different potentially between CPA and UAS.

The candidate factors for UAS classification were examined in two groups: those factors that are currently used in 14CFR for CPA, followed by those factors proposed for UAS, as identified in Table 6 . The rationale follows the original hypothesis for this work. That is, if the factors used in the current aircraft class/aircraft category classification for CPA are reasonable and sufficient for UAS, then those factors should serve as a reasonable starting point for UAS classification. However, if those factors do not adequately capture either distinct design attributes of UAS or operational aspects that warrant different standards, then other factors should be considered. As noted in the previous section, additional factors beyond those in the CFR have been proposed by various organization to capture a different aspect of risk that is more significant in unmanned aviation. This set provides a good starting point, if additional classification factors seem warranted for UAS.

Table 7 presents the results of the analysis of the factors that were identified in 14CFR for CPA classification. This analysis was a 2-step process: first determining which of the four aspects of risk (likelihood, severity, duration, and expectation) is most qualitatively affected by a perturbation of each factor (all others being held equal) for CPA operations in the NAS, and second by assessing whether a reasoned argument could be formed to justify the conclusion that the factor would have similar or different effects on the components of risk of UAS operation in the NAS. As shown in this table, many factors affect the same aspect of risk in both manned and unmanned aircraft. The obvious example is that as weight increases, safety risk increases in both manned and unmanned aircraft, assuming all other factors being equal. Thus, such factors could be used to partition UAS in the same way as they are used presently.

On the other hand, and more importantly, differences in the table point to potential factors for CPA classification that may not be applicable or relevant in the same respects. Those differences lend support to refuting the hypothesis that the current classification system is suitable for UAS. Number of passenger seats, for example, obviously does not apply to UAS at the present time, since passenger-carrying UAS are a far term application. When such passenger-carrying UAS are proposed, the number of passenger seats will be a significant classification factor. Factors that affect risk differently may require modification in how they are used for unmanned aviation. For instance, multiple engines are common in both CPA and unmanned aircraft. However, the variation in UAS designs (e.g., quadcopters) is much more extensive than for CPA. In addition, some UAS have very different engine types (e.g., solar-electric) to meet unique mission requirements (e.g., mission times on the order of days). Those UAS may operate quite differently than manned aircraft with multiple engines, and hence require different minimum design standards. 
Another difference highlighted in the table is maneuverability. It is quite difficult to confidently assess whether maneuverability is needed to distinguish different groups of UAS. Maneuverability is used to distinguish between the normal, utility, and acrobatic categories in manned aviation. Maneuverability will be critical for UAS to accomplish avoidance and recovery maneuvers. For UAS, it is not obvious what normal flying might mean, and whether there will be a need for different structural capabilities in UAS to support acrobatic maneuvers. This factor may have significant unknowns until the UAS industry fully matures and the certification community can develop correlations between maneuverability and usage. Finally, the motivation for use factor may have a different effect for CPA than for UAS. For a CPA, compensated operations are held to a higher standard. There is an expectation that compensated aviation services operate in a rigorous, professional manner, consistent with the higher standard. Compensated operations may still be significant in unmanned aviation, though in a different way. Assuming UAS operation mix is similar to CPA, compensated operations will be more common than uncompensated ones, so to keep the total number of adverse events down, the likelihood must be controlled.

Table 7. Differences in Effect on Risk of Airworthiness Classification Factors from 14CFR

\begin{tabular}{|l|c|c|}
\hline \multirow{2}{*}{\begin{tabular}{l} 
Factorworthiness Classification \\
\cline { 2 - 3 } Weight
\end{tabular}} & Frimary Aspect of Risk Affected by each Factor \\
\hline Number and type of engines & Severity & For UAS \\
\hline Maneuverability & Likelihood & $\begin{array}{c}\text { Severity } \\
\text { significant unknowns }\end{array}$ \\
\hline Number of passenger seats & Likelihood & Unknown \\
\hline Scheduled operations & Severity & Not applicable \\
\hline Frequency of operations & Likelihood & Likelihood \\
\hline Motivation for use & Likelihood & Likelihood \\
\hline Responsible party & Expectation & Likelihood \\
\hline
\end{tabular}

Overall, it seems reasonable to postulate that the primary factors from 14CFR (except for number of passenger seats) may affect UAS classification for design standards, but not exactly in the same way as CPA. That is, most of the airworthiness classification factors from 14CFR are still useful, but probably in different ways. It is not surprising then that a large number of organizations ${ }^{6}$ have developed classification approaches that do not rely solely on the existing regulations for CPA. As such, it seems reasonable to explore other factors that have been proposed for UAS classification.

Table 8 presents a cursory analysis of UAS-specific classification factors culled from the survey. Clearly each factor was deemed relevant to UAS classification from at least one organization. This analysis, consequently, simply consists of an initial assessment of each factor, considered individually, in three areas: the aspect of risk affected by this factor (comparable to Table 7), benefits of this factor with regard to UAS airworthiness classification, and potential issues with each factor. As shown in Table 8, the potential benefit for many of the factors reflects the wider range of design diversity in UAS than CPA. Different airworthiness standards may be needed to account for different design aspects that support that range. For example, a highly frangible UAS may have very different requirements with respect to structures and materials than one that is not intended to be frangible. Other factors, like operational area and overflown area, account for hazards to people and property in a way that is not necessary for any aircraft with a human on-board. Those factors might be considered in operational limitations that could partition UAS into categories different from CPA. Cost, albeit an unconventional factor, strongly correlates with quality aspects of a UAS that affect safety risk (e.g., structural integrity and reliability) perhaps more directly so than for CPA.

The potential issues largely come in three forms: clarity, agreement, and enforceability-characteristics important to a useable classification scheme. Clarity issues reflect the fact that some concepts are easy to give a name to, but establishing an objective, general, universal definition of the concept is very difficult. For instance, there is a means to determine avionics complexity in the advisory circular ${ }^{11}$ for 23 CFR 1309 . However, the authors of this definition recognize that "experienced engineering and operational judgment" is needed to determine if a system is complex. In essence, there is currently no objective definition of complexity. To resolve clarity issues further research regarding the factor should be expected. An issue of agreement is one where the UAS community generally understands the factor, although the precise definition has not been established. Since these definitions may have business implications and larger societal concerns, the appropriate way to resolve these issues will likely involve public hearings and industry-consensus standards processes (e.g., RTCA subcommittees). Finally, the 
notion of enforceability is considered. These are issues where the regulatory body would need to provide some level of continuing enforcement that the aircraft does not violate the terms of their certification regarding the classification factor. To be clear, issues suggested in Table 8 should not be taken to mean that these factors are not viable. Instead, these issues should be considered if the Table 8 factors are used to discriminate between groups of UAS in any classification approach.

Table 8. Analysis of UAS-Specific Classification Factors

\begin{tabular}{|c|c|c|c|}
\hline & $\begin{array}{l}\text { Primary Aspect of Risk } \\
\text { Affected by the Factor }\end{array}$ & $\begin{array}{l}\text { Potential Benefits of Factor } \\
\text { for Classification }\end{array}$ & $\begin{array}{l}\text { Potential Issues with the } \\
\text { Factor }\end{array}$ \\
\hline $\begin{array}{l}\text { Avionics } \\
\text { Complexity }\end{array}$ & Likelihood & $\begin{array}{l}\text { May account for increased } \\
\text { dependence on safety-critical } \\
\text { avionics }\end{array}$ & Clarity in defining complex \\
\hline Airspeed & Severity & $\begin{array}{l}\text { May account for expanded } \\
\text { design space for UAS }\end{array}$ & $\begin{array}{l}\text { Requires agreement in } \\
\text { maximum airspeed definition }\end{array}$ \\
\hline Kinetic Energy & Severity & $\begin{array}{l}\text { May account for the amount of } \\
\text { damage that can be inflicted } \\
\text { upon people or other property } \\
\text { on impact }\end{array}$ & $\begin{array}{l}\text { Requires agreement in } \\
\text { maximum speed definition }\end{array}$ \\
\hline $\begin{array}{l}\text { Operational } \\
\text { Range (visual) }\end{array}$ & Likelihood & $\begin{array}{l}\text { May account for new hazards } \\
\text { related to using ground } \\
\text { observers }\end{array}$ & $\begin{array}{l}\text { Enforceability concerns; } \\
\text { Clarity in defining loss of } \\
\text { visual contact by occlusions }\end{array}$ \\
\hline $\begin{array}{l}\text { Operational } \\
\text { Range (radio) }\end{array}$ & Likelihood & $\begin{array}{l}\text { May account for new hazards } \\
\text { from using radio control links }\end{array}$ & Enforceability concerns \\
\hline Frangibility & Severity & $\begin{array}{l}\text { May allow reduced accident } \\
\text { severity through frangible } \\
\text { structures that would be } \\
\text { unacceptable for CPA }\end{array}$ & $\begin{array}{l}\text { Clarity in defining } \\
\text { frangibility }\end{array}$ \\
\hline $\begin{array}{l}\text { Operational } \\
\text { Area }\end{array}$ & Likelihood & $\begin{array}{l}\text { May account for hazards } \\
\text { specific to airspace } \\
\text { participants }\end{array}$ & Enforceability concerns \\
\hline Overflown Area & Severity & $\begin{array}{l}\text { May account for hazards to } \\
\text { people and property on the } \\
\text { ground }\end{array}$ & $\begin{array}{l}\text { Enforceability concerns; } \\
\text { Clarity in defining lightly } \\
\text { inhabited areas }\end{array}$ \\
\hline $\begin{array}{l}\text { Operational } \\
\text { Failure } \\
\text { Consequence }\end{array}$ & Severity & $\begin{array}{l}\text { May account for new hazards } \\
\text { and risk assessment unique to } \\
\text { UAS }\end{array}$ & $\begin{array}{l}\text { Clarity in elaborating } \\
\text { relevant failures }\end{array}$ \\
\hline Altitude & Likelihood & $\begin{array}{l}\text { May account for potential } \\
\text { design differences for UAS } \\
\text { propulsion or structural aspects } \\
\text { relevant to flying at altitudes } \\
\text { different from CPA }\end{array}$ & Enforceability concerns \\
\hline Flight Time & Duration & $\begin{array}{l}\text { May account for new hazards } \\
\text { related to substantially } \\
\text { different mission times (longer } \\
\text { or shorter) for UAS }\end{array}$ & $\begin{array}{l}\text { Requires agreement in } \\
\text { definition of flight time }\end{array}$ \\
\hline Aircraft Cost & Severity & $\begin{array}{l}\text { May account for the quality of } \\
\text { a UAS, in a way that is not } \\
\text { necessary for CPA, since } \\
\text { existing regulations for safety } \\
\text { guarantee a level of quality. }\end{array}$ & $\begin{array}{l}\text { Clarity in defining aircraft } \\
\text { cost; Unprecedented use of } \\
\text { cost in } 14 \mathrm{CFR}\end{array}$ \\
\hline
\end{tabular}




\section{Concluding Remarks}

There are more things in heaven and earth, Horatio, than are dreamt of in your philosophy. - William Shakespeare in Hamlet

As Hamlet admonishes his friend about having a perspective that is too simple to account for the complexities of life, this work indicates that there may be both physical aircraft and operational attributes, not considered for manned aircraft, that warrant consideration when contemplating how airworthiness standards are to be allocated to UAS. This allocation of standards to a group of UAS is referred to as UAS classification. This research examined the hypothesis that the classification approach used for manned aircraft today is appropriate for UAS if the factors used to group manned aircraft are sufficient for grouping UAS for the purpose of assigning appropriate airworthiness standards. If those factors do not adequately capture either distinct design attributes of UAS or operational aspects that merit different standards, then other factors should be considered.

A study of 14CFR shows that the conventional classes of aircraft, such as airplanes (i.e., fixed wing), rotorcraft, and balloons, align quite well with the vast majority of types of UAS currently under consideration. Conventional aircraft categories and subcategories may not align as well, based on an analysis of the factors that form the basis for those categories. Twenty candidate factors were identified that may have some effect on how aircraft with similar design and operational characteristics could be grouped together. Each factor is described and analyzed. Aircraft weight is a common dimension used in classification, although weight is rarely used exclusively. From a survey of UAS classification approaches in a related technical report ${ }^{6}$, most notional classification systems include operational dimensions to their classification system, such as the intended operational area. The analysis in this paper shows that many of the UAS-specific factors capture different risks than those factors from 14CFR, albeit with significant issues to be resolved. If these issues are resolved, then those factors may be useful in extending the existing classification system to accommodate UAS. However, until these issues are resolved, an incremental step towards the introduction of UAS may be to include some operational limitations to a UAS certification basis. This approach is analogous to a "restricted category" airworthiness certificate for CPA.

This paper presents a small step in advancing the cause of UAS classification for airworthiness. Many more research steps must be taken before a sound, scientifically informed decision may be made regarding UAS classification. Some steps include a comprehensive analysis of the individual factors, as well as analysis of the factors in combination, to better understand how they may characterize hazards and risks for UAS.

\section{Acknowledgements}

The authors gratefully acknowledge the guidance and insight provided by Dr. Natasha Neogi of the National Institute of Aerospace in Hampton, Virginia, USA.

\section{References}

${ }^{1}$ Government Accountability Office, "Unmanned Aircraft Systems: Measuring Progress and Addressing Potential Privacy Concerns Would Facilitate Integration into the National Airspace System." September 18, 2012. GAO-12-981

${ }^{2}$ DeGarmo, M. T., "Issues Concerning Integration of Unmanned Aerial Vehicles in Civil Airspace." MITRE Technical Report, November 2004.

${ }^{3}$ Department of Defense, Handbook, “Airworthiness Certification Criteria,” MIL-HNBK-516B, 26 September 2005.

${ }^{4}$ Cork, L. R., Clothier, R. A., Gonzalez, L. F., and Walker, R. A. "The Future of UAS: Standards, Regulations, and Operational Experiences.” IEEE Aerospace and Electronic Systems Magazine, November 2007.

${ }^{5}$ Clothier, R., Palmer, J., Walker, R., and Fulton, N. "Definition of an Airworthiness Categories for Unmanned Aircraft Systems (UAS)" 27 International Congress of the Aeronautical Sciences (ICAS), 19-24 September 2010.

${ }^{6}$ Maddalon, J. M., Hayhurst, K. J., Koppen, D. M., Upchurch, J. M., Morris, A. T., Verstynen, H. A., "Perspectives on Unmanned Aircraft Classification for Civil Airworthiness Standards.” NASA TM-2013-217969. 2013.

${ }^{7}$ Federal Aviation Administration, "FAA Safety Risk Management Policy", FAA Order 8040.4A, 30 April 2012.

${ }^{8}$ ICAO, “Unmanned Aircraft Systems (UAS).” Circular 328-AN/190. March 2011.

${ }^{9}$ ICAO, “Annex 8 to Convention on International Civil Aviation, $11^{\text {th }}$ edition." July 2010.

${ }^{10}$ McCormick, G. F., "Certification of Civil Avionics." In the Digital Avionics Handbook, Second edition, Chapter 7, CRC Press, 2007.

${ }^{11}$ Federal Aviation Administration, "System Safety Analysis and Assessment for Part 23 Airplanes." Advisory Circular 23.1309-1E. 17 Nov 2011.

${ }^{12}$ Unmanned Vehicle Systems International, 2012 UAS Yearbook, 10th Edition, Blyenburgh \& Co, June 2012.

${ }^{13}$ Federal Aviation Administration, "Part 23 Certification Process Study: Recommendations for General Aviation for the Next 20 Years." July 2009. 
${ }^{14}$ European Aviation Safety Agency. "Policy Statement: Airworthiness Certification of Unmanned Aircraft Systems (UAS)," E.Y013-01, 2009. 